\title{
RESPONSABILIDADE CIVIL PELA PERDA DE UMA CHANCE NO DIREITO DO TRABALHO - ESTUDO DE CASOS
}

\section{LIABILITY FOR LOSS OF A CHANCE IN THE LABOUR LAW - CASE STUDY}

\section{Resumo}

O presente artigo tem como objetivo a análise da teoria da responsabilidade civil pela perda de uma chance, que vem ganhando destaque no Brasil, em razão das crescentes demandas que abordam o tema. Analisa-se a natureza jurídica do dano decorrente desse tipo de responsabilidade, que, embora não haja uma concordância nos âmbitos doutrinário e jurisprudencial, observa-se uma tendência a considerá-lo como uma espécie autônoma de dano, desconectado dos danos materiais (danos emergentes e lucros cessantes) e morais. Pretende-se analisar, ainda, sua incidência na jurisprudência pátria, em especial na esfera trabalhista, em que, apesar de não haver uma legislação específica que trate do tema, aplicando-se as normas civilistas que dispõe sobre a responsabilidade civil, o tema não passa despercebido, havendo inúmeras ações que tem por objeto a indenização em comento. Desta feita, considerando que a aplicação da teoria depende da análise do caso concreto, pretende-se fazer uma pesquisa sobre os posicionamentos dos Tribunais pátrios sobre a questão, tomando-se como fonte alguns precedentes das principais Cortes Regionais Trabalhistas do país.

Palavras-Chave: Responsabilidade civil. Perda de uma chance. Indenização. Direito do Trabalho.

\begin{abstract}
This article aims to analyze the theory of responsibility for loss of a chance, which is gaining prominence in Brazil, due to the increasing demands that address the theme. Analyzes the legal nature of the damage from this type of responsibility that, although there is no agreement in the areas of doctrine and jurisprudence, there is a tendency to regard it as a kind of damage autonomous, disconnected from materials damage (emerging damage and loss of profits) and moral. Intend to analyze also its impact on
\end{abstract}


patriotic jurisprudence, particularly in labor justice, in which, although there is no specific legislation that addresses the issue, applying the standards civilists which provides for civil responsibility, the subject is not goes unnoticed, with numerous actions whose purpose is to indemnification under discussion. This way, considering that the application of the theory depends on the analysis of the case, it is intend to research on the positions of patriotic Courts on the issue, taking some precedent as a source of the major Regional Labor Courts of the country.

Keywords: Civil Responsibility. Loss of a Chance. Indemnification. Labor Law.

\section{INTRODUÇÃO}

Por muito tempo o direito ignorou a possibilidade de se responsabilizar o causador de um dano decorrente da perda da oportunidade de obtenção de um resultado favorável ou de se evitar um prejuízo, com fundamento na suposta ausência de certeza quanto à obtenção da situação jurídica mais favorável.

A jurisprudência, da mesma forma, não vislumbrava a possibilidade de dano pela perda de uma chance, sobretudo em razão da impossibilidade de produção de prova inequívoca de que, se não fosse a ocorrência do evento que se diz danoso, teria a vítima alcançado a oportunidade que alega perdida.

Nos últimos anos, porém, houve uma evolução doutrinária e jurisprudencial acerca do tema, passando-se, então, a admitir a existência de responsabilidade civil pela perda de uma chance.

Todavia, por se tratar de uma matéria ainda pouco difundida no meio jurídico, ainda há muita controvérsia e discussão a envolvendo, não tendo, sobretudo no âmbito dos Tribunais pátrios, se formado uma linha uniforme de pensamento.

E é exatamente por isso que o tema merece especial atenção dos operadores do direito, com vistas a harmonizar conceitos e definir parâmetros, a fim de aprimorar a aplicação da teoria.

O presente trabalho tem, portanto, a finalidade de contribuir para a evolução da aplicabilidade da responsabilidade civil pela perda de uma chance, com enfoque especial no âmbito do Direito do Trabalho, onde se tem verificado um aumento de demandas que tratam do assunto. 
O presente artigo busca abordar, portanto, o histórico da teoria, os seus pressupostos gerais e, por fim, examinar casos concertos, de modo a verificar de que a forma a jurisprudência pátria tem tratado o assunto.

\section{RESPONSABILIDADE CIVIL PELA PERDA DE UMA CHANCE}

\subsection{Surgimento da teoria}

A teoria da responsabilidade civil pela perda de uma chance tem origem no direito estrangeiro, mais precisamente na França. Surgiu em virtude da análise de casos concretos, em que se acreditava que, através de uma conduta humana que privasse outrem de obter esperada vantagem ou de se evitar um prejuízo, o autor da conduta deveria ressarcir os danos provocados, mesmo se não fosse certa a ocorrência do evento futuro.

Embora a maioria da doutrina afirme que o instituto originou-se em meados dos anos 60, na França, há relatos de que o primeiro caso de aplicação da teoria da perda de uma chance ocorreu em 17 de julho de 1889, quando a Corte de Cassação Francesa conferiu indenização pela atuação culposa de um oficial ministerial que extinguiu todas as possibilidades de a demanda lograr êxito mediante seu normal procedimento.

Como pioneira, a França passou a aplicar o instituto em casos de chances perdidas em matéria contenciosa, em jogos de azar, em competições esportivas, em perdas de chances de obter uma melhoria na qualidade de vida, e até mesmo em casos médicos, como se demonstra, abaixo:

\footnotetext{
A Corte de Cassação referendou julgado da Corte de Paris, condenou-se cirurgião que se fez assistir, durante a cirurgia, por outro médico não especialista em anestesia. Durante a indução anestésica, efetuada por este último, a paciente sofreu uma crise de apnéia, seguida de distúrbios cardíacos. Transportada, em coma, ao hospital, a mulher morreu dias mais tarde. A culpa do cirurgião foi reconhecida pelos peritos da Corte de Paris, por falta de diligencia, o cirurgião ocasionou a perda de uma chance de sobrevivência à paciente (KFOURI NETO, 2002, p. 104).
}

Tal instituto também ganhou destaque na Itália, que passou a reconhecer o dano independentemente do resultado final. 
Inicialmente, foi estudado pelo professor italiano Giovanni Pacchioni, em sua obra Diritto Civile Italiano, na qual analisava hipóteses clássicas da responsabilidade civil pela perda de uma chance citadas na doutrina francesa, como o caso de um jóquei cujo cavalo não foi entregue a tempo de participar de uma competição; um pintor cuja obra de arte foi extraviada por culpa do correio, não podendo participar de uma exposição; dentre outros.

No entanto, chegou-se à conclusão que as situações descritas, embora desagradáveis, não eram passíveis de causar dano patrimonial. O professor descartou, portanto, a possibilidade de indenização pela perda de uma chance.

Foi Adriano de Cupis, também professor italiano, em 1966, que vislumbrou um dano independente de um resultado final, concluindo, em seu estudo de casos, que em todos eles a vitória não era certa, mas existia uma possibilidade de ser alcançada, o que justificava a indenização.

Para o italiano, não há como negar, naqueles casos, a existência da possibilidade de vitória antes da ocorrência do fato danoso. Não obstante, enquadra a chance da vitória como espécie de dano emergente, conforme leciona:

\begin{abstract}
A vitória é absolutamente incerta, mas a possibilidade de vitória, que o credor pretendeu garantir, já existe, talvez em reduzidas proporções, no momento em que se verifica o fato em função do qual ela é excluída: de modo que se está em presença não de um lucro cessante em razão da impedida futura vitória, mas de um dano emergente em razão da atual possibilidade de vitória que restou frustrada (DE CUPIS, apud SAVI, 2009, p. 11).
\end{abstract}

A respeito da aplicação da teoria no sistema jurídico da Itália, Sérgio Savi (2009, p. 25) descreve o primeiro caso ali julgado:

\footnotetext{
Uma empresa denominada Stefer convocou alguns trabalhadores para participar de um processo seletivo para a contratação de motoristas que iriam compor seu quadro de funcionários. Após terem se submetido a diversos exames médicos, alguns candidatos ao emprego foram impedidos pela Stefer de participar das demais provas (de direção e de cultura elementar), que seriam necessárias à conclusão do processo de admissão.
}

Diante desses fatos, o juiz de primeiro grau reconheceu o direito dos autores de serem admitidos sob a condição de que superassem as provas que não fizeram, condenando a empresa à indenização pelo atraso no processo de admissão. Foi a primeira aplicação do instituto na Itália e, apesar de a sentença ter sido reformada pelo Tribunal de Roma, foi confirmada, posteriormente, pela Corte de Cassação, que 
ratificou o dano pela perda de uma chance, ou seja, pela perda da possibilidade de os candidatos serem admitidos na empresa.

O instituto também foi utilizado na Inglaterra, em 1911, no caso Chaplin vs Hicks, que tratou da chance perdida por uma candidata a um concurso de miss que foi impedida de participar da etapa final.

No Brasil, os primeiros casos que trataram da questão e que foram postos à apreciação do Judiciário são da década de 90, e foram encontrados no Tribunal de Justiça do Rio Grande do Sul, havendo importantes julgados de relatoria do Desembargador Ruy Rosado de Aguiar Júnior que abordam o tema, sendo oportuno citar um caso em que um advogado foi responsabilizado pelo extravio dos autos de uma demanda ajuizada por uma senhora que buscava receber pensão do órgão previdenciário, em razão da morte de seu marido (Apelação Cível n. 591064837).

No âmbito dos Tribunais Superiores, o primeiro caso que teve destaque nacional foi o relatado no julgamento do RESP 788.459/BA, realizado pela $4^{\text {a }}$ Turma do STJ, em $08 / 11 / 2005$.

A demanda envolvia uma participante do programa do apresentador Silvio Santos, denominado "Show do Milhão", que chegou à última etapa do concurso ali promovido e, para alcançar o prêmio de um milhão de reais, deveria responder corretamente à pergunta que lhe foi apresentada.

Ocorre que, posta a pergunta para a participante, esta não encontrou uma resposta correta e, portanto, optou por não respondê-la e manter o prêmio já conquistado, no importe de quinhentos mil reais. Posteriormente, a participante teve notícia de que a pergunta que poderia levar ao prêmio máximo do programa não tinha resposta correta e, como base nisso, ajuizou a demanda, com vistas à obtenção de uma indenização decorrente da chance frustrada.

O Superior Tribunal de Justiça reconheceu que a autora tinha, de fato, a possibilidade de obter uma situação jurídica mais favorável, caso lhe houvesse sido apresentada uma pergunta que contivesse uma resposta correta. E, com base nesse fato, ou seja, na constatação de um dano decorrente da perda de uma chance, a Turma Julgadora deferiu à autora uma indenização, que foi fixada considerando as possibilidades de acerto da pergunta final do programa. Assim, havendo quatro opções de resposta para a pergunta, a participante tinha a possibilidade de acerto correspondente a $25 \%$, o que levou à fixação da indenização em $25 \%$ do valor do prêmio que poderia ter a autora alcançado. 


\title{
2.2 Conceito
}

A perda de uma chance, no sentido jurídico, decorre de uma probabilidade séria e real de obtenção de lucro ou de se evitar um prejuízo, ou seja, trata-se da perda da possibilidade de se alcançar uma situação jurídica mais favorável.

Com propriedade, nos ensina o autor Sérgio Cavalieri Filho (2008, p. 74-75), a respeito da teoria

\begin{abstract}
Caracteriza-se essa perda de uma chance quando, em virtude da conduta de outrem, desaparece a probabilidade de um evento que possibilitaria um benefício futuro para a vítima, como progredir na carreira artística ou militar, arrumar um melhor emprego, deixar de recorrer de uma sentença desfavorável pela falha do advogado, e assim por diante. Deve-se, pois, entender por chance a probabilidade de se obter um lucro ou de se evitar uma perda.
\end{abstract}

Como se vê, o agente não é responsabilizado por ter causado um dano direto e imediato à vítima, mas sim por tê-la privado de obter uma possível vantagem ou, em decorrência de sua omissão, por ter sido impossível evitar a perda de uma vantagem.

Nas lições de Vera Fradera (apud LUZ, Ariane Innocente; PEREIRA JUNIOR), a responsabilidade pela perda da chance

(...) vem a ser uma espécie de responsabilidade pré-contratual fundada basicamente na noção de possibilidade potencial da conquista de determinada vantagem como fruto de um contrato ou mesmo de tratativas preliminares à celebração da avença.

Assim, quando há um processo em curso no qual o indivíduo busca a obtenção de certa vantagem, ou evitar um futuro dano, e, em decorrência da atitude de um terceiro infrator, seja comissiva ou omissiva, o processo é interrompido, causando a impossibilidade de obtenção do resultado esperado, tem-se a ocorrência da perda de uma chance.

Necessário perceber que a perda de uma chance somente ocorrerá quando a conduta do infrator extinguir todas as possibilidades de o vitimado agir em busca do resultado almejado ou de evitar o prejuízo. Assim, se houver qualquer meio passível de reverter a situação, não é cabível a aplicação da teoria.

Ademais, deve-se tratar de prejuízo, material ou imaterial, resultante de fato consumado, e não hipotético. 
Deve-se olhar a chance como a perda da possibilidade de conseguir um resultado ou de se evitar um dano; devem-se valorar as possibilidades que o sujeito tinha de conseguir o resultado para ver se são ou não relevantes para o ordenamento. Essa tarefa é do juiz, que será obrigado a fazer, em cada caso, um prognóstico sobre as concretas possibilidades que o sujeito tinha de conseguir o resultado favorável (CAVALIERI FILHO, 2008, p. 75).

Importante frisar que a aplicação da teoria não é cabível em qualquer perda de oportunidade. $\mathrm{O}$ instituto refere-se a uma perda de chance séria e real, sendo imprescindível a demonstração do prejuízo, o qual não pôde ser evitado.

Sobre a possibilidade de indenização pela chance perdida quanto à obtenção de um benefício ou para se evitar um prejuízo, hialinas são as palavras de Sérgio Severo(1996, p. 13-14):

(...) é essencial que a mesma seja plausível e não aponte uma simples quimera, como ensina Le Tourneau. E, adiante, reforça: “(...) esta chance deveria ser seria e viável. (...) Portanto, a chance deve ser considerável e não meramente eventual. O montante indenizatório também deve ser correspondente ao total do benefício que possivelmente ocorreria ou das perdas que poderiam ser evitadas. Na estipulação de tal montante, deve ser levada em conta a probabilidade de que tal sucedesse, sendo indenizado o percentual de que foi privada a vítima, ou seja, o juiz apreciará, então, não o valor global dos ganhos ou perdas, mas a proporção deste valor que em concreto representa a frustração da chance, que é atribuível ao agente segundo as circunstâncias do caso.

Ainda, conforme lição de Cavalieri Filho (2008, p/ 75), seguindo a doutrina italiana, "a perda de uma chance somente será indenizável se houver a probabilidade de sucesso superior a cinquenta por cento, de onde se conclui que nem todos os casos de perda de uma chance são indenizáveis".

Já em sentido contrário, Rafael Peteffi da Silva (2009, p. 142) pondera

Parece-nos bastante compreensível que o direito italiano tenha ficado isolado
nesse entendimento, já que existem inúmeros casos em que se pode
identificar, com razoável grau de certeza, que a vítima tenha perdido, por
exemplo, 20\%, $30 \%$ ou $40 \%$ das chances de alcançar determinado objetivo.
Nessas hipóteses, não teríamos nenhum argumento sólido para negar o
provimento destas ações de indenização.

Corroborando o último entendimento, crê-se que a indenização é devida em decorrência da perda da oportunidade de obter uma vantagem, e não pela perda da própria vantagem, pelo que deve ser concedida mesmo que a probabilidade não atinja o patamar de $50 \%$, bastando apenas minorar o montante indenizatório, na proporção do prejuízo sofrido. 
Nesse sentido, complementa Sérgio Savi (2009, p. 63)

\begin{abstract}
Para a valoração da chance perdida, deve-se partir da premissa inicial de que a chance no momento de sua perda tem um valor certo que, mesmo sendo de difícil determinação, é incontestável. É, portanto, o valor econômico desta chance que deve ser indenizado, independente do resultado final que a vítima poderia ter conseguido se $\mathrm{o}$ evento não a tivesse privado daquela possibilidade.
\end{abstract}

A quantificação do dano, portanto, deverá ser feita de forma equitativa pelo juiz, devendo observar o percentual de probabilidade de obtenção da vantagem esperada, tomando como base o valor do resultado útil esperado.

\title{
2.3 Natureza jurídica
}

Não é pacífico na doutrina e na jurisprudência o entendimento a respeito da natureza jurídica do dano decorrente da perda de uma chance, havendo divergências quanto à sua caracterização como lucro cessante, dano emergente, dano moral ou, ainda, como um dano autônomo.

Autores como Carlos Alberto Menezes Direito e Sérgio Cavaliere Filho (2005, p. 96) entendem que o dano decorrente da perda de uma chance é uma espécie de lucro cessante, na medida em que corresponde ao valor que a vítima deixou de auferir, ou seja, é a perda do lucro esperável, que se baseia na certeza daquilo que ela ganharia no prosseguimento normal de suas atividades.

Tal posicionamento é criticado, de forma acertada, por um dos principais conhecedores do tema, Sérgio Savi (2009, p. 14), que, embora reconheça terem os lucros cessantes e o dano pela perda de uma chance características comuns, não se confundem, na medida em que, quando se tem uma hipótese de lucro cessante, é certo o ganho futuro da vítima, havendo incerteza, apenas, quanto ao seu valor.

Por outro lado, quando se constata a perda de uma chance, não há lucro esperável, mas apenas uma probabilidade de que a vantagem poderia ser obtida pela vítima.

Nas palavras de Savi (2009, p. 15) “A perda de uma chance decorre da violação a um mero interesse de fato, enquanto o lucro cessante deriva de uma lesão a um direito subjetivo". 
No caso de lucros cessantes, o autor deverá fazer prova não do lucro cessante em si considerado, mas dos pressupostos e requisitos necessários para a verificação deste lucro. Já nas hipóteses de perda de uma chance, se permanecerá sempre no campo do desconhecido, pois, em tais casos, o dano final é, por definição, indemonstrável, mesmo sob o aspecto dos pressupostos de natureza constituinte (SAVI, 2009, p. 17).

Há, também, estudiosos que concebem o dano decorrente da perda de uma chance como espécie de dano emergente, na medida em que a chance perdida seria um prejuízo distinto do resultado final, mas é algo que já pertencia ao indivíduo no momento da perda.

Configura dano emergente a efetiva diminuição dos bens da vítima à época do evento danoso, denominado, também, dano positivo, conforme leciona Diniz (2003, p. 66):

Dano positivo ou emergente, que consiste num déficit real e efetivo no patrimônio do lesado, isto é, numa concreta diminuição em sua fortuna, seja porque se depreciou o ativo, seja porque aumentou o passivo, sendo, pois, imprescindível que a vítima tenha, efetivamente, experimentado um real prejuízo, visto que não são passíveis de indenização danos eventuais(...). Tais prejuízos se traduzem num empobrecimento do patrimônio atual do lesado pela destruição, deterioração, privação do uso e gozo, etc., de seus bens existentes no momento do evento danoso.

Defendendo esta classificação, Duque e Fonseca (2011) asseveram que

Se a premissa é a de que só se pode indenizar o dano estético, o dano moral ou a perda patrimonial, percebe-se que a indenização pela perda de uma chance está contida nessa premissa, uma vez que, por ser algo real, ela já faz parte do patrimônio do indivíduo e, ao se perder, reduz seu patrimônio. $\mathrm{Ou}$ seja, há uma certeza do dano e, assim, ele se molda de maneira a ser considerado um dano emergente, encaixando-se perfeitamente no critério de perda patrimonial.

Para os adeptos desta ideia, a chance perdida representa um dano presente, em razão da perda da oportunidade de se obter uma situação melhor no futuro, o que comprova a certeza dos danos causados à vítima.

Com efeito, as dúvidas inerentes à certeza do dano e à existência do nexo de causalidade seriam afastadas em razão da evidência da lesão à vítima, configurada na perda da oportunidade de se obter um lucro ou de se evitar um prejuízo, se não fosse à interferência do agente causador do dano (SAVI, 2009, p. 18-19). 
Ocorre que, como já asseverado, o dano decorrente da perda de uma chance advém de uma probabilidade, e não de uma certeza, e, também por essa razão, não se vislumbra a possibilidade de concebê-lo como dano emergente.

Noutro norte, há autores que defendem ser a perda de uma chance uma espécie de dano moral, levando-se em conta a inexistência de parâmetros objetivos capazes de determinar o valor indenizatório devido, considerando a dor da vítima. Estar-se-ia, pois, diante de um dano não passível de aferição pecuniária.

Ressalte-se que muitos Tribunais têm aplicado o instituto como espécie de dano moral, por assim o entender, em certos casos, e, em outros, por confundir equivocadamente os institutos, o que será analisado mais adiante.

Por fim, tem-se a parte da doutrina que reputa o dano decorrente da perda de uma chance como uma espécie de dano autônomo, desvinculado das classificações anteriores, sendo oportuno citar, como defensores desta tese, Sérgio Savi (2009) e Raimundo Simão de Melo(2006).

Por conseguinte, o dano advindo da perda de uma chance constitui uma espécie de dano autônomo, situada entre o dano emergente e o lucro cessante, posição que ora se perfilha.

Imperioso ressaltar que essa terceira espécie de indenização pode englobar tanto os danos materiais como os extrapatrimoniais. Nas palavras de Raimundo Simão de Melo (2006):

\footnotetext{
É claro que, além da indenização material, enquadrada nessa terceira e sui generis espécie, a vítima pode sofrer dano moral, também passível de reparação. Igualmente não se pode esquecer de que o ato ilícito que gerou a indenização pela perda de uma chance pode acarretar outros prejuízos materiais por dano emergente propriamente dito, passível de reparação. É o caso, por exemplo, de um atleta corregedor que está a poucos metros da bandeirada final que lhe daria, com séria chance, a vitória em primeiro lugar, mas que é agarrado por uma pessoa que o impede de continuar na disputa. Com esse ato retira-se-lhe a oportunidade de ser vitorioso. Há prejuízo pela perda da chance e por danos morais, mas esse atleta pode ainda ficar traumatizado e doente e ter que se submeter a sério tratamento médico e psicológico para poder voltar a correr, pois o abalo foi tão grande que atingiu a saúde física e psíquica do mesmo. Com as despesas desse tratamento deverá arcar o autor do ato, como é evidente, que tem natureza de dano emergente.
}

E, mesmo com o impasse doutrinário acerca da natureza jurídica do dano pela perda de uma chance, há de se frisar que a indenização só terá cabimento nos casos em que se tratar de oportunidade real e séria. 


\subsection{Critérios para aplicação da responsabilidade civil pela perda de uma chance}

De início, o critério imprescindível para a caracterização da perda de uma chance é a seriedade da oportunidade perdida. É justamente a chance perdida, que conforme já narrado, deve ser real e séria, que irá distingui-la dos demais danos eventuais ou hipotéticos.

Somente com a comprovação de que caso não houvesse acontecido o infortúnio, causado por terceiro, a vítima teria uma séria e real chance de conseguir o resultado pretendido, ou evitar o prejuízo, resta configurada a responsabilidade decorrente da perda da chance.

Além de a chance perdida ser real e séria, o deferimento da indenização depende da presença dos demais pressupostos da responsabilidade civil comum, distinguindo-se, apenas, o objeto da indenização, que não corresponde a um ganho ou perda reais, mas consiste na perda da oportunidade de melhora na situação jurídica da vítima.

Assim, para que se caracterize a perda de uma chance, são necessários a conduta culposa do agente, o resultado que se perdeu (chance) e o nexo causal entre ambos.

Observa-se que não é necessário o dano certo e determinado, basta que exista um prejuízo à vítima decorrente da legítima expectativa que possuía em obter certo benefício ou evitar determinado prejuízo.

No que diz respeito ao quantum indenizatório, é necessário levar em conta a probabilidade de obtenção de determinada vantagem, e não a vantagem em si.

Muitos Tribunais, conforme se verá adiante, reconhecem a ocorrência de efetiva perda de chance, mas, ao fixar o montante da indenização, o fazem de acordo com o valor da vantagem perdida ou do prejuízo suportado, incorrendo em grave equívoco, já que não havia certeza quanto ao alcance da situação mais favorável.

Desta feita, importante se mostra o estudo de casos concretos, a fim de se possa verificar de que forma a teoria tem sido aplicado pelos julgadores.

\section{APLICAÇÃo da TEORIA DA PERDA DE UMA CHANCE NO ÂMBITO TRABALHISTA - ESTUDO DE CASOS}

Embora seja a inegável autonomia do direito juslaboral, as relações com o direito civil não se amainaram, mantendo-se sólidas em inúmeras circunstâncias, como 
no caso em estudo, que, em virtude da omissão acerca da responsabilidade civil na legislação trabalhista, aplica-se a legislação civilista que trata do tema, por força do artigo 769 da CLT.

Considerando que o tema ainda é controvertido e a análise acerca da existência de uma chance séria e real deve ser feita diante do caso concreto, nada melhor do que analisar de que forma as Cortes Especializadas vêm decidindo as demandas que envolvem o tema.

No que diz respeito à natureza jurídica do dano, verifica-se uma tendência à adoção da concepção de que o dano decorrente da perda de uma chance é uma terceira modalidade ou gênero, ou seja, que se trata de dano autônomo.

Nesse sentido já se posicionou o Tribunal Regional do Trabalho da $1^{\text {a }}$ Região, nos autos do processo 0017100-96.2008.5.01.0401, em decisão proferida por sua Décima Turma, que entendeu que "a indenização pela perda de uma chance ou de uma oportunidade vem sendo entendida pela doutrina como um tertium genus na teoria da responsabilidade civil”.

O Tribunal Regional do Trabalho da $3^{a}$ Região, da mesma forma, já emitiu, por meio de sua Oitava Turma, pronunciamento no sentido de que o dano pela perda de uma chance é um terceiro gênero, conforme se verifica do seguinte precedente:

\footnotetext{
RESPONSABILIDADE CIVIL - INDENIZAÇÃO PELA PERDA DE CHANCE. Recente construção doutrinária está evoluindo para uma terceira modalidade de dano, com base na responsabilidade civil prevista nos arts. 186 e 927 do Código Civil. Refere-se à indenização pela "perda de uma chance ou oportunidade", quando a vítima é privada da oportunidade de obter certa vantagem, em face de ato ilícito praticado por terceiro, configurando-se um prejuízo material indenizável, consubstanciado na real probabilidade de um resultado favorável esperado, caso não fosse obstado pela conduta ilegal do ofensor.
}

Há casos, ainda, que o mesmo fato gera, para a vítima, no entender do julgador, o direito à indenização pela perda de uma chance, por danos materiais e por danos morais, de forma cumulativa.

É o que se verifica, por exemplo, da ação trabalhista n. 00035-2011-012-03-003, analisada, em sede de recurso ordinário, pela Sétima Turma do Regional Mineiro, cuja ementa se transcreve a seguir:

RECURSO ORDINÁRIO. INDENIZAÇÃO PELA PERDA DE UMA CHANCE. Demonstrado nos autos não só a promessa de emprego por parte da empresa, como também, a prática de ato que levou o autor a uma 
legítima expectativa de contratação, em estrita violação ao princípio da boa fé objetiva, o deferimento de indenização pela perda de uma chance é medida que se impõe, a qual deverá reparar os danos sofridos pelo demandante quanto à "perda da oportunidade de concretização da vitória esperada, in casu, a contratação e prestação de serviços em prol da Reclamada.

O caso trata de um trabalhador, aprovado em processo seletivo realizado por uma empresa, que pediu demissão do emprego anterior e, todavia, quando se apresentou para iniciar a prestação de serviços, foi surpreendido com a informação de que sua contratação não seria efetivada, por problemas internos da empresa.

O Colegiado, não vislumbrando justo motivo para a não contratação do obreiro, condenou a reclamada ao pagamento de indenizações por danos materiais (correspondente ao aviso prévio indenizado e ao saldo constante da conta vinculada do FGTS, acrescido da multa de $40 \%$, os quais o reclamante receberia em caso de dispensa sem justa causa); por danos morais no valor de $\mathrm{R} \$ 27.140,00$; e pela perda de uma chance, no importe de $\mathrm{R} \$ 66.000,00$ (equivalente à abrangência do novo salário que em tese o empregado perceberia na demandada, pelo período de seis meses).

Embora muito bem fundamentado o respeitável acórdão, entende-se ser discutível a indenização por danos materiais ali fixada, considerando que não havia certeza de que, se o autor tivesse permanecido no emprego anterior, seria dispensado sem justa causa pela ex-empregadora, o que foi dado como certo pela Turma Julgadora.

Da mesma forma, é discutível a existência de efetiva perda de uma chance na hipótese examinada pelo Tribunal Mineiro, assim como o valor atribuído à respectiva indenização, o qual acabou por corresponder ao prejuízo suportado pelo trabalhador, e não à perda da possibilidade de obter aquela vantagem.

Aliás, no âmbito trabalhista, casos como o acima citado, que dizem respeito a promessas de emprego frustradas, as quais levam os trabalhadores a criar uma expectativa de contratação, que não se concretiza na prática, são os mais comuns de serem observados e é aí que residem as maiores controvérsias a respeito da aplicação da teoria.

Há reiteradas decisões que reconhecem a responsabilidade da empresa précontratante, sobretudo quando se verifica a não formalização do contrato após o obreiro ter-se submetido a processo seletivo, exame admissional e outras tratativas preliminares. É o que se verifica do julgamento dos seguintes recursos ordinários, todos provenientes do Tribunal Regional do Trabalho da $3^{\text {a }}$ Região: 00035-2011-012-03-00-3; 01741-2011042-03-00-4 e 0122200-80.2009.5.01.0247. 
O entendimento dos Tribunais, em casos desse tipo, é no sentido de que a chance séria e real perdida pela vítima corresponde à contratação frustrada que, caso tivesse se efetivado, possibilitaria ao obreiro usufruir das vantagens advindas do novo contrato de emprego.

Deve-se observar, porém, que há bons argumentos para se defender a inexistência de perda de uma chance nessas hipóteses. Isso porque não se vislumbra uma probabilidade de contratação, ou seja, uma possibilidade de melhora na situação jurídica. Na verdade, tendo o obreiro sido aprovado em processo seletivo, a tendência, se tudo tivesse ocorrido da forma esperada, seria o vínculo empregatício se formar, ou seja, havia uma certeza de que isso ocorreria, e não apenas uma mera probabilidade, como ocorre nos casos de perda de uma chance.

Assim, a não efetivação da contratação, por ato ilícito da empresa précontratante, embora seja passível de ressarcimento, já que implica um indiscutível dano patrimonial, não induz ao direito à indenização pela perda de uma chance.

Por outro lado, se um trabalhador é impedido de participar de um processo seletivo por ato ilícito de sua ex-empregadora, conforme relatado no processo $\mathrm{n}$. 00628 2011-028-03-00-5, também oriundo do Regional Mineiro, fica mais clara a efetiva perda de uma chance.

$\mathrm{Na}$ ação acima referida, o reclamante foi excluído do processo de seleção do qual participava, em razão de sua carteira de trabalho ter sido retida pela exempregadora. Vislumbrou-se, portanto, a perda da possibilidade de o autor ser aprovado no processo seletivo e, assim, de ser contratado para a vaga que estava sendo disputada.

A certeza da contratação, nesse caso, não existia, pois dependia da aprovação do candidato no processo seletivo, que, apesar de não ser certa, poderia ocorrer. $O$ Colegiado, neste feito, condenou a ex-empregadora do reclamante ao pagamento de indenização pela perda de uma chance, no valor de $\mathrm{R} \$ 3.200,00$, que corresponde a um terço do salário do cargo para o qual havia se candidatado, pelo período de doze meses. Veja-se a ementa do julgado:

INDENIZAÇÃO POR DANOS MATERIAIS - PERDA DE UMA CHANCE. Demonstrado que a exclusão do reclamante de processo seletivo para emprego decorreu única e exclusivamente da ausência de baixa na CTPS pela antiga empregadora, inegável o enquadramento da conduta da ré no conceito de ato ilícito constante do art. 186 do CC/02, qual seja, a "ação ou omissão voluntária, negligência ou imprudência", por meio da qual se viola direito de outrem, causando-lhe dano. Sendo assim, há de se imputar à reclamada a responsabilidade por tal chance perdida, uma vez estarem 
presentes os pressupostos comuns da responsabilidade civil e os específicos requisitos dessa espécie de responsabilização (a probabilidade séria e concreta de efetivação do resultado esperado e a verificação da perda de uma chance).

Com efeito, quando se constata, no caso concreto, que o trabalhador perdeu a oportunidade de participar de processo seletivo em razão da ausência de baixa em sua carteira de trabalho ou de outro fato imputável ao ex-empregador, verifica-se efetiva perda de uma chance séria e real, apta a ensejar reparação pecuniária.

Também é comum, no âmbito laboral, que a indenização pela perda de uma chance se funde no fato de o empregado ter contraído doença ocupacional ou ter sofrido acidente de trabalho, que o tenha impedido de ascender na carreira ou de auferir melhor remuneração.

Como exemplo tem-se a ação trabalhista n. 00348-2006-512-04-00-0, que tramitou junto ao Tribunal Regional do Trabalho da $4^{\mathrm{a}}$ Região, na qual uma bancária pleiteava, dentre outras verbas, indenização pela perda de uma chance, decorrente do fato de ter contraído uma doença ocupacional que a impediu de ascender na carreira.

Oportuno citar alguns trechos da sentença prolatada no feito, que foi mantida, neste ponto pelo Eg. Tribunal, em sede de recurso ordinário, por ter tratado da questão de forma bastante clara e bem fundamentada:

\begin{abstract}
No caso dos autos, é possível caracterizar a impossibilidade de ascensão profissional da reclamante como perda de uma chance. Na verdade, quando alguém contrai uma doença relacionada às atividades laborativas, caso da autora, fica incapacitado para o trabalho, tendo reduzida ou até mesmo eliminada sua inserção no mercado laborativo. A autora, inicialmente desempenhou a função de escriturária e, após, caixa-executiva, ficando impedida de crescer profissionalmente por conta da doença. A reclamada é uma instituição financeira federal, constituída sob a forma de empresa pública, de forma que os seus empregados possuem estabilidade no emprego, senão absoluta, ao menos relativa, já que a demandada se submete aos princípios da Administração Pública, notadamente o princípio da motivação, que veda o desligamento de empregados senão por meio de ato devidamente motivado. A par disso, a reclamante era detentora de nível superior e possuía experiência em anos de serviços prestados à reclamada. Esses fatores demonstram que ela possuía chance real e séria de vir a ocupar cargo de maior destaque e com melhor remuneração, se o curso normal dos fatos não fosse interrompido pela doença de natureza incapacitante por ela adquirida.
\end{abstract}

Como se vê, no caso em comento, havia uma chance séria e real de a autora ser promovida para uma função de gerência, o que foi obstado pela doença laboral que a acometeu, residindo nesse fato a culpa da empregadora. 
Ademais, a indenização pela perda de uma chance, na hipótese, foi fixada de forma correta, tendo o Julgador tomado por base o efetivo rendimento financeiro que a reclamante auferiria em caso de promoção, além de ter considerado a probabilidade de o evento ocorrer. Atentou-se o Magistrado, portanto, para o fato de que o valor da indenização deve corresponder à perda da oportunidade de se obter determinada vantagem, e não à vantagem em si.

Há casos, ainda, que, constatada a culpa da empregadora no acidente de trabalho sofrido pelo trabalhador, se vislumbra a ocorrência de dano decorrente da perda de uma chance por esse fato.

Como exemplo, cita-se o julgado do Tribunal Regional do Trabalho da $1^{\mathrm{a}}$ Região, proferido nos autos da ação trabalhista n. 0139400-25.2007.5.01.0521, em que o reclamante, por força de acidente de trabalho, sofreu amputação do polegar esquerdo, o que gerou incapacidade temporária para o trabalho, com percepção de benefício previdenciário pago pelo INSS.

Alegou o reclamante ter ficado impedido de majorar seus ganhos salariais pela realização de horas extras, por uma promoção ou pela obtenção de uma nova colocação no mercado, o que foi acolhido pelo egrégio Regional do Rio de Janeiro, que fixou a indenização pela perda de uma chance no valor correspondente a um salário por mês de afastamento previdenciário, parcelas vencidas e vincendas, limitada ao montante de $\mathrm{R} \$ 60.000,00$, além de indenização por danos morais no valor de $\mathrm{R} \$ 20.000,00$.

A hipótese, data vênia, não retrata a perda de uma possibilidade séria e real de obtenção de uma vantagem, mas a demonstração de um prejuízo material, passível de ser indenizado, mas não sob o fundamento de perda de uma chance.

Veja-se, inclusive, que a indenização foi fixada com base no valor do salário auferido pelo obreiro, multiplicado pelo tempo de afastamento previdenciário, configurando, pois, ressarcimento por um dano material e não pela perda da possibilidade de obtenção de uma situação jurídica mais favorável.

Outro caso interessante, que envolve a teoria ora estudada, foi encontrado na jurisprudência do Tribunal Regional do Trabalho da $17^{\mathrm{a}}$ Região, quando do julgamento da ação trabalhista n. 00809.2009.014.17.00.8, em que foi verificado que a reclamante perdeu a possibilidade de receber o benefício de complementação de aposentadoria de forma integral, ante a constatação de que foi coagida a aderir ao plano antecipado de afastamento voluntário (PAAV) oferecido pela ex-empregadora. Para melhor 
elucidação, citam-se fragmentos do acórdão proferido pela $2^{\mathrm{a}}$ Turma da Corte do Espírito Santo:

\begin{abstract}
No caso em comento, a autora perdeu a chance de obter a integralidade da complementação de sua aposentadoria através do plano de previdência complementar da Fundação Baneses, ante a edição das Resoluções 696/2008 e 697/2008, que praticamente a obrigaram a participar do Plano Antecipado de Afastamento Voluntário - PAAV -, sob pena de dispensa sem justa causa.(...) É induvidoso que se a empresa não houvesse exigido o pedido de demissão da autora, ela permaneceria no emprego até completar o período aquisitivo para a complementação integral da aposentadoria. Isso porque basta uma breve leitura da ficha funcional da obreira (fls.68/69) para constatar que ela era uma funcionária exemplar, sempre avaliada de forma positiva, inclusive recebendo elogios de clientes "pela maneira atenciosa e profissional que os trata, facilita o atendimento e gera satisfação dos mesmos." (fl. 68-v). Destarte, plenamente cabível a indenização pela perda da chance de obter a complementação de aposentadoria integral, não se vislumbrando qualquer violação aos dispositivos legais invocados pelo réu. Dou provimento, para condenar o réu ao pagamento de indenização por perda de uma chance, no valor de R\$50.000,00.
\end{abstract}

Ao exame do caso concreto, verifica-se que a reclamante possuía a chance séria e real de completar o período necessário à aquisição do direito à percepção da complementação de aposentadoria de forma integral, o que foi obstado por ato ilícito do empregador, que a compeliu a aderir ao plano de demissão voluntária em momento anterior, sendo esse mais um exemplo de aplicação correta da teoria em estudo.

Há, ainda, casos em que o empregado é obstado, por ato ilícito da empresa, de concorrer à eleição para cargo de representação que lhe conferiria estabilidade provisória no emprego.

Nesse sentido, cita-se o julgamento proferido pela Oitava Turma do Tribunal Regional do Trabalho da $3^{\text {a }}$ Região, nos autos da ação trabalhista n. 01405-2008-07703-00-0, em que um trabalhador foi dispensado do emprego, durante o período estabilitário decorrente do cumprimento de mandato como membro da comissão de prevenção de acidentes (CIPA), um dia antes da apresentação do registro de candidatura a um novo pleito. Veja-se o seguinte trecho do acórdão:

Conjugando todos esses elementos, não há como deixar de se presumir que a reclamada efetivamente quis, ao dispensar o reclamante imotivadamente, impedir sua candidatura às eleições da CIPA 2008/2009, assim obstando que adquirisse, caso eleito, nova estabilidade. Caso contrário, ao constatar, após sua dispensa, que o empregado era estável, porque não tentou reintegrá-lo? É o que se dessume do depoimento do preposto à fl. 88 .

(...) Nessa direção, recente construção doutrinária evolui para uma terceira modalidade de dano, com base na responsabilidade civil prevista nos arts. 186 e 927 do Código Civil. Refere-se à indenização pela "perda de uma 
chance ou oportunidade", quando a vítima é privada da oportunidade de obter certa vantagem, em face de ato ilícito praticado por terceiro, configurando-se um prejuízo material indenizável.

Não há dúvida que, na hipótese, havia uma chance séria e real de o trabalhador ser eleito membro da CIPA, caso lhe houvesse sido oportunizado o registro da candidatura, o que não ocorreu por ato ilícito da ex-empregadora. Trata-se, portanto, de outro exemplo de perda de uma chance no âmbito laboral, corretamente aplicada pelo Regional Mineiro, inclusive quanto ao valor arbitrado à indenização, que não correspondeu à vantagem perdida pelo autor, mas à perda da possibilidade de obtê-la.

Também no âmbito do Regional Mineiro, encontrou-se outro interessante caso que trata da responsabilidade civil pela perda de uma chance. Segundo relato constante da ação trabalhista n. 01533-2007-112-03-00-5, o autor foi impedido, pela exempregadora, de ocupar cargo de maior destaque na empresa, mesmo depois de ter sido aprovado em processo seletivo interno, em razão de dispensa por justa causa perpetrada de forma arbitrária pela empresa. Veja-se:

\begin{abstract}
Na hipótese, está provado neste processo que o reclamante logrou ser aprovado em processo seletivo interno realizado pela reclamada para ser promovido à vaga de supervisor de operação de televendas que tinha como remuneração mensal um valor que correspondia ao dobro do salário que recebia.

(...)

O reclamante tinha, portanto, como justa e real a existência da oportunidade de ser promovido a supervisor de vendas e auferir ganho salarial correspondente a $100 \%$ dos seus ganhos mensais. Mas viu perdida a chance de conquistar esse resultado em razão de ato ilícito praticado pela reclamada, consistente na sua dispensa abusiva e ilícita, quando foi injustamente acusado de cometer falta grave, situação que não se confirmou na esfera da realidade dos fatos, conforme veio de demonstrar a prova do processo, matéria já examinada neste recurso, e à qual remeto as partes, evitando-se o enfadonho da repetição. (...) Está-se, pois, diante de um dano do qual decorre a frustração de uma esperança, a perda de uma oportunidade viável e real que o reclamante esperava legitimamente.
\end{abstract}

O reclamante, no caso, tinha a possibilidade de obter vantagem pecuniária decorrente do exercício das atribuições de supervisor, cujo salário era superior ao que auferia na ré, o que não se realizou pela dispensa arbitrária e ilícita perpetrada pela exempregadora.

Embora não houvesse certeza quanto à obtenção da vantagem, já que não havia como prever por quanto tempo o trabalhador se manteria no cargo, não há dúvida de que existia uma chance séria e real de que suas parcelas rescisórias, em caso de término do 
liame empregatício, fossem calculadas com base no salário do cargo para o qual foi promovido e, todavia, foi impedido de assumir.

Deve-se atentar, ainda, para o fato de que muitas demandas são ajuizadas com vistas à obtenção de indenização pela perda de uma chance, quando esta sequer existia concretamente.

Nesse sentido, oportuno citar dois precedentes do Tribunal Regional do Trabalho da $3^{\text {a }}$ Região, a saber, 00060-2012-027-03-00-7 e 00806-2010-033-03-00-2.

No primeiro caso, o reclamante foi dispensado imotivadamente e de forma antecipada, durante a vigência do contrato de experiência. Alegava fazer jus à indenização pela perda de uma chance, porquanto se demitiu do emprego anterior para firmar contrato com a reclamada.

A Quarta Turma do Regional Mineiro entendeu, acertadamente, que a situação não configura perda de uma chance, já que a contratação do obreiro se efetivou, ainda que por meio de contrato de experiência. E, ademais, a continuidade do vínculo depende de outros fatores, não sendo possível imputar à ré a prática de conduta ilícita, já que a rescisão do contrato é uma faculdade da qual pode dispor.

Confira-se o seguinte trecho do acórdão:

\begin{abstract}
A dispensa imotivada e antecipada do obreiro, que se encontra cumprindo contrato de experiência, não faz nascer o direito à indenização por danos morais e materiais, vez que tal situação se encontra nos limites dos poderes do empregador, principalmente em se considerando que a reclamada foi condenada ao pagamento da indenização pela rescisão antecipada do contrato de trabalho (f. 96).

E mais. Na hipótese em questão, tenho que também deve ser

afastada a arguição de indenização pela perda de uma chance, pois ficou claro que a reclamada cumpriu sim a promessa realizada, contratando o autor, ainda que por meio de contrato de experiência. Todavia, não tem a empregadora a obrigação de dar continuidade ao contrato de trabalho, tão menos de indicar os motivos que levaram à rescisão antecipada, devendo sim arcar com todas as verbas trabalhistas decorrentes da extinção do vínculo, como ocorreu no caso dos autos.
\end{abstract}

Já no segundo precedente, o reclamante foi deslocado de Minas Gerais, onde tem residência, para o Estado da Bahia, local em que estava sendo realizada obra da empresa que o pretendia contratar, e lá se submeteu a testes admissionais, tendo, no final, sido reprovado.

A Quinta Turma Julgadora da Corte Trabalhista de Minas Gerais entendeu, de forma correta, que o não preenchimento dos requisitos técnicos necessários ao exercício 
do cargo pretendido não significa efetiva perda de uma chance. Veja-se a ementa do julgado:

\footnotetext{
INDENIZAÇÃO POR DANOS MORAIS. PERDA DE CHANCE. FASE PRÉ-CONTRATUAL. TESTE DE APTIDÃO. INEXISTÊNCIA DE ATO ILÍCITO. A indenização por perda de uma chance é devida quando o lesado, por ato ilícito do responsável, tem frustrada uma vantagem futura e certa, ocasionando-se aqueles danos ao patrimônio jurídico, de ordem material ou moral. Na forma da lei, é inerente ao poder empresarial exigir dos candidatos a emprego em seus quadros de pessoal a satisfação de condições objetivas mínimas, o que se justifica pela busca constante de qualidade na execução dos objetivos empresariais, com o máximo de eficiência, vedada qualquer forma de discriminação. Não comete ato ilícito, a rejeição de candidato ao emprego que não atende as condições exigidas para o cargo, não sendo por isto devidas indenizações por danos materiais e morais, decorrentes da fase de pré-contratação, ainda mais, quando, no caso, o empregado não faz qualquer prova de ter perdido chance de nova colação profissional.
}

Com efeito, o que se percebe, depois de uma breve pesquisa no âmbito da jurisprudência de alguns Tribunais Trabalhistas do país, é que a teoria da responsabilidade civil pela perda de uma chance, por vezes, é aplicada de forma equivocada, seja porque confundida com um dano material ou um dano moral, seja porque a indenização arbitrada não leva em conta a perda da possibilidade de obtenção da vantagem, mas a própria vantagem.

Todavia, não se pode olvidar que as Cortes tëm, pouco a pouco, aprimorado a aplicação da teoria, havendo, sobretudo nos casos mais recentes, brilhantes decisões tratando do tema, o que demonstra que a jurisprudência está em constante ascensão, de modo a acompanhar a evolução das relações sociais e do próprio Direito, por via de consequência.

\section{CONCLUSÃO}

Conforme exposto no presente trabalho, a aplicação da teoria da responsabilidade civil pela perda de uma chance tem ganhado espaço no Brasil, sobretudo diante da crescente complexidade da sociedade, que demanda soluções alternativas às tradicionalmente previstas no ordenamento jurídico.

E, para que se tenha uma chance perdida passível de indenização é necessário que, ao exame da hipótese concreta, se verifique a possibilidade séria e real de obtenção 
de uma vantagem ou de se evitar um prejuízo, que tenha sido obstada por ato ilícito cometido pelo agente causador do dano.

Além disso, demonstrou-se que, embora ainda haja decisões em sentido contrário, vislumbrou-se, na maioria dos julgados ora analisados, que o dano decorrente da perda de uma chance é identificável, autônomo e totalmente distinto do resultado final, não podendo ser confundido com um mero dano material ou moral.

$\mathrm{Na}$ esfera trabalhista, embora a jurisprudência ainda não tenha adotado um posicionamento uniforme para tratar do tema, sobretudo porque a aplicação da teoria depende da análise do caso concreto, tem evoluído de modo significativo, com vistas a acompanhar as crescentes demandas que tratam da questão.

E, de posse de alguns julgados, verificou-se uma aplicação confusa do instituto, sobretudo quando da fixação do valor da indenização correlata. Mas, por outro lado, não se pode deixar de notar uma certa evolução, havendo, sobretudo na jurisprudência mais recente, brilhantes decisões tratando do tema.

O presente trabalho teve, portanto, a finalidade de reafirmar a necessidade de se dar continuidade ao estudo em torno do tema, que tem incontroversa relevância social, a fim de que seja possível, num futuro breve, obter-se a harmonização dos requisitos e critérios de aplicação da teoria, sobretudo no seio da jurisprudência, onde ainda não há parâmetros bem definidos para sua incidência.

\section{REFERÊNCIAS}

BRASIL. Congresso Nacional. Código Civil. Lei No 10.406 de 10 de Janeiro de 2002.DOU, Brasília, DF, 11 janeiro de 2002. IN: Vade Mecum. $9^{a}$ ed. São Paulo: Saraiva, 2010.

BRASIL. Congresso Nacional. Constituição da República Federativa do Brasil. DOU No 191-A, Brasília, DF, 5 de Outubro de 1988. IN: Vade Mecum. 9ª ed. São Paulo: Saraiva, 2010.

BRASIL. Distrito Federal, Superior Tribunal de Justiça, Recurso Especial n. 788.459/BA. $4^{\text {a }}$ turma, Recorrente: BF Utilidades Domésticas LTDA, Recorrida: Ana Lúcia Serbeto de Freitas Matos, Rel. Min. Hélio Quaglia Barbosa, 08/11/2005. Disponível em <http://www.stj.jus.br>. Acesso em abr. 2013.

BRASIL. Espirito Santo. Tribunal Regional do Trabalho da $17^{a}$ Região, Recurso Ordinário n. 00809.2009.014.17.00.8, 2ª turma, Recorrente Ercilia de Souza Lana. Recorrido Banestes S.A.. Relator Desembargador: Claudio Armando Couce de Menezes, 20 abr. 2012. Disponível em <http://www.trt17.jus.br>. Acesso em abr. 2013. 
BRASIL, Minas Gerais, Tribunal Regional do Trabalho da $3^{\text {a }}$ Região, Recurso Ordinário n. 00035-2011-012-03-00-3, 7ª turma, Recorrente: Empa S.A. Serviços de Engenharia. Recorrido: Bruno de Oliveira Rosa. Relator Desembargador: Marcelo Lamego Pertence, 02 jun. 2011. Disponível em <http://www.trt3.jus.br >. Acesso em abr. 2013.

BRASIL. Minas Gerais, Tribunal Regional do Trabalho da $3^{\text {a }}$ Região, Recurso Ordinário n. 00060-2012-027-03-00-7, 4 4arma, Recorrente: Jackson Alves de Oliveira. Recorridos: Teksid do Brasil Ltda e HJR Recursos Humanos Ltda. Relatora Juíza Convocada Taisa Maria Macena de Lima, 6 fev. 2013. Disponível em <http://www.trt3.jus.br>. Acesso em mai. 2013.

BRASIL. Minas Gerais, Tribunal Regional do Trabalho da $3^{\text {a }}$ Região. Recurso Ordinário n. 0000806-78.2010.5.03.0033, $1^{a}$ turma, Recorrente: José Márcio Souza. Recorridos: JMI Montagem E Manutenção Industrial LTDA e Consórcio Rio Paraguaçu. Relator Desembargador Maurílio Brasil, 22 fev. 2011. Disponível em <http://www.trt3.jus.br>. Acesso em mai. 2013.

BRASIL. Minas Gerais, Tribunal Regional do Trabalho da $3^{\text {a }}$ Região, Recurso Ordinário n. 01405-2008-077-03-00-0-RO. 8a turma, Recorrentes: Associação Hospitalar Santa Rosalia e Ademildo Aires Schiffner. Recorridos: os mesmos, Rel. Des. Cleube de Freitas Pereira, 13/05/2009. Disponível em <http://www.trt3.jus.br>. Acesso em abr. 2013.

BRASIL. Minas Gerais, Tribunal Regional do Trabalho da $3^{\text {a }}$ Região, Recurso Ordinário n. 00628-2011-028-03-00-5, $1^{\mathrm{a}}$ turma, Recorrente: Wall Mart Brasil Ltda. Recorrido: Evander Moura De Lana. Relator Desembargador:Paulo Maurício Ribeiro Pires, 14.mai 2012. Disponível em <http://www.trt3.jus.br>. Acesso em mai. 2013.

BRASIL. Minas Gerais, Tribunal Regional do Trabalho da $3^{\text {a }}$ Região.Recurso Ordinário n. 0122200-80.2009.5.01.0247, $1^{\mathrm{a}}$ turma, Recorrente: Hypermarcas S/A. Recorrido Diane Moreira Neves. Relator Desembargador: Paulo Marcelo de Miranda Serrano, 20 set. 2011. Disponível em <http://www.trt3.jus.br>. Acesso em abr. 2013.

BRASIL. Minas Gerais, Tribunal Regional do Trabalho da $3^{\text {a }}$ Região. Recurso Ordinário n. 01533-2007-112-03-00-5, 7 ${ }^{\mathrm{a}}$ turma, Recorrente: MAXSWELL LOPES SILVA. Recorrido: A \& C CENTRO DE CONTATOS S/A. Relator Desembargador: Emerson Jose Alves Lage, 02. Out. 2010. Disponível em <http://www.trt3.jus.br>. Acesso em abr. 2013.

BRASIL. Minas Gerais, Tribunal Regional do Trabalho da $3^{\text {a }}$ Região. Recurso Ordinário n. 01741-2011-042-03-00-4, 9 a turma, Recorrentes: Locplan Locacao De Equipamentos E Servicos Ltda. E Mauricio Tadeu Mendonca Nogueira. Recorridos: os mesmos. Relator Desembargador: Monica Sette Lopes,19 jun. 2012. Disponível em <http://www.trt3.jus.br>. Acesso em abr. 2013.

BRASIL. Paraná, Tribunal Regional do Trabalho da 9a Região, Recurso Ordinário n. 04308-2011-022-09-00-3, $7^{\text {a }}$ turma, Recorrente: Jose Marcos da Silva. Recorrido: Órgão de Gestão de Mão - de - obra do Trabalhador Portuário e Avulso do Porto 
Organizado de Paranaguá. Relator Desembargador: Rosalie Michaele Bacila Batista, 06.set.2012. Disponível em <http://www.trt9.jus.br>. Acesso em mai. 2013.

BRASIL. Rio de Janeiro, Tribunal Regional do Trabalho da $1^{\text {a }}$ Região, Recurso Ordinário n. 0017100-96.2008.5.01.0401, 10ª turma, Recorrente: Condomínio do Eco Resort de Angra, Recorridos: Renan das Virgens Dantas e Blue Tree Park Hotels, Relator Desembargador: Marcos Cavalcante, 04.ago.2010. Disponível em <http://www.trt1.jus.br>. Acesso em abr. 2013.

BRASIL. Rio de Janeiro, Tribunal Regional do Trabalho da $1^{\text {a }}$ Região, Recurso Ordinário n. 0139400-25.2007.5.01.0521, $3^{\mathrm{a}}$ turma, Recorrente: Santa Casa da Misericórdia de Resende Recorrido: Benedito de Souza., Relator Desembargador: Giselle Bondim Lopes Ribeiro, 08 fev. 2012. Disponível em <http://www.trt1.jus.br>. Acesso em mai. 2013.

BRASIL. Rio Grande do Sul, Tribunal de Justiça do Rio Grande do Sul, Apelação Cível

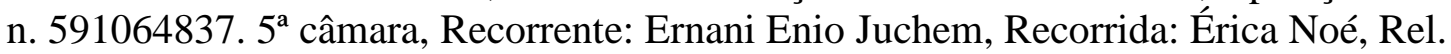
Des. Ruy Rosado de Aguiar Junior, 29/08/1991. Disponível em <http://www.tjrs.jus.br>. Acesso em abr. 2013.

BRASIL. Rio Grande do Sul, Tribunal Regional do Trabalho da $4^{\mathrm{a}}$ Região, Recurso Ordinário n. 00348-2006-512-04-00-0, $3^{\mathrm{a}}$ turma, Recorrente: Caixa Econômica Federal Recorrido: Rosangela Oselame Postal. Relator Desembargador: Denise Pacheco, 17 out. 2007. Disponível em <http://www.trt4.jus.br>. Acesso em abr. 2013.

CAVALIERI FILHO, Sérgio. Programa de Responsabilidade Civil. 8. ed. São Paulo: Atlas, 2008.

DE PLÁCIDO E SILVA. Vocabulário Jurídico IV. Rio de Janeiro: Forense, 1989.

DINIZ, Maria Helena. Curso de direito civil brasileiro: responsabilidade civil. $17^{\mathrm{a}} \mathrm{ed}$. São Paulo: Saraiva, 2003, v. 7.

DIREITO, Carlos Alberto Menezes; CAVALIERI FILHO, Sérgio. Comentários ao novo Código Civil, vol. XIII. Rio de Janeiro: Forense, 2005, p. 96.

DUQUE, Bruna Lyra; FONSECA, Cesar Augusto Martinelli. A teoria pela perda de uma chance e a sua caracterização como dano emergente. In: Âmbito Jurídico, Rio Grande, XIV, n. 95, dez 2011. Disponível em: <http://www.ambitojuridico.com.br/site/index.php?n_link=revista_artigos_leitura\&artigo_id=10782>. Acesso em abr. 2013.

FRADERA, apud LUZ, Ariane Innocente; PEREIRA JUNIOR, Hamilton. O reconhecimento da responsabilidade civil pela perda de uma chance na seara trabalhista, Disponível em <http://pt.scribd.com/doc/56601145/O-Reconhecimento-Da-

Responsabilidade-Civil-Pela-Perda-de-Uma-Chance-Na-Seara-Trabalhista $>$. Acesso em abr/2013. p. 02.

KFOURI NETO, Miguel. Culpa Médica e Ônus da Prova. São Paulo: Revista dos Tribunais, 2002. 
LUZ, Ariane Innocente; PEREIRA JUNIOR, Hamilton. O reconhecimento da responsabilidade civil pela perda de uma chance na seara trabalhista. Disponível em <http://pt.scribd.com/doc/56601145/O-Reconhecimento-Da-ResponsabilidadeCivil-Pela-Perda-de-Uma-Chance-Na-Seara-Trabalhista> Acesso em abr/2013.

MELO. Raimundo Simão de. Direito Ambiental do Trabalho e a Saúde do Trabalhador - Responsabilidades: Danos material, moral, estético e pela perda de uma chance. 2. ed. São Paulo: LTr, 2006.

MELO. Raimundo Simão de. Indenização pela perda de uma chance. Boletim Jurídico, Uberaba, ano 5, n. 224. Disponível em: <http://www.boletimjuridico.com.br/ doutrina/texto.asp?id=1785> Acesso em: 2 abr. 2013.

NORONHA, Fernando. Direito das obrigações. Fundamentos do Direito das obrigações: Introdução à responsabilidade civil. 2. ed. rev. e atual. São Paulo: Saraiva, 2007.

RODRIGUES, Silvio. Direito civil: responsabilidade civil. 19. ed. São Paulo: Saraiva, 2003.

SAVI, Sérgio. Responsabilidade civil por perda de uma chance. São Paulo: Atlas, 2009.

SEVERO, Sérgio. Os Danos Extrapatrimoniais. São Paulo: Saraiva, 1996.

SILVA, Rafael Peteffi da. Responsabilidade civil pela perda de uma chance: uma análise do direito comparado e brasileiro. 2. ed. São Paulo: Atlas, 2009. 